\title{
UECTC-RE T2-S3-0345
}

\section{AMMONIA-WATER ABSORPTION CYCLE FOR TRANSPORTATION OF LOW- GRADE THERMAL ENERGY OVER LONG DISTANCE}

\author{
Qiang MA \\ Institute of Refrigeration and \\ Cryogenics, \\ Shanghai JiaoTong University, \\ Shanghai, 200240, China \\ maq@sjtu.edu.cn
}

\author{
Lingai LUO \\ LOCIE, Polytech'Savoie, \\ Campus Scientifique, \\ Savoie Technolac, 73376, \\ Le Bourget-Du-Lac, France \\ lingai.luo@univ-savoie.fr
}

\author{
Ruzhu WANG \\ Institute of Refrigeration and \\ Cryogenics, \\ Shanghai JiaoTong University, \\ Shanghai, 200240, China \\ rzwang@sjtu.edu.cn
}

\section{ABSTRACT}

This paper presents the thermodynamic and hydrodynamic feasibility of the application of the ammonia-water absorption system for transportation of low-grade thermal energy over long distance. A model is built and analyzed, and it shows satisfactory and attractive results. When a steam heat source at the temperature of $120^{\circ} \mathrm{C}$ is available, the user site can get hot water output at about $55^{\circ} \mathrm{C}$ with the thermal COP of about 0.6 and the electric COP of about 100 in winter, and cold water output at about $8^{0} \mathrm{C}$ with the thermal COP of about 0.5 and the electric COP of 50 in summer. A small-size prototype is built to verify the performance analysis. Basically the experimental data show good accordance with the analysis results. The ammonia-water absorption system is a potential prospective solution to utilize the waste heat which locates far away.

\section{INTRODUCTION}

Energy conservation and environmental protection issues have gained more and more attention all over the world. The research to make more efficient use of the waste heat from industry plants and power stations is getting a fast growth. However, the waste heat sites and the user sites are usually located apart from each other. The absence of efficient ways to overcome the long-distance transportation problem leads to great difficulties to use this great deal of waste heat. In order to transport low-grade waste heat energy for domestic cooling or heating use, various technologies have been developed, including chemical reversible reactions ${ }^{[1]}$, phase change thermal energy storage and transportation by vehicles or pipelines ${ }^{[2-4]}$, hydrogen absorbing alloys ${ }^{[5-8]}$, solid-gas chemical adsorption ${ }^{[9-}$ ${ }^{10]}$, liquid-gas absorption ${ }^{[11-13]}$, and etc. In recent years, the adsorption and the absorption have been got much attention, and the ammonia-water absorption technology is a potential solution.
The experimental work on transportation of heat energy over long distance by ammonia-water absorption has not been reported much. In this study, a model is developed to evaluate the feasibility of the heat transporting system, and a small-size experimental prototype is built to investigate its performance.

\section{WORKING PRINCIPLE OF THE SYSTEM AND THE MODELING DESCRIPTION}

Figure 1 shows the schematic diagram of the ammoniawater absorption cycle for a long-distance heat energy transportation system. The waste heat is injected into the generator and the rich solution is separated into the ammonia vapor and the weak solution, and then the ammonia vapor is condensed in the condenser. The weak solution and the ammonia liquid are transported through pipelines from the source site to the user site. At the user site the liquid ammonia evaporates in the evaporator to produce cold, or the weak solution absorbs the ammonia vapor in the absorber to produce heat. The rich solution formed in the absorber is then transported back to the generator. Thus there are three liquids which are transported, the ammonia liquid, the weak solution and the rich solution. The heat exchanger at the source site recuperates the heat of the weak solution from the generator, and the heat exchanger at the user site recuperates the heat of the rich solution from the absorber. In this way, the heat energy is stored into the concentration difference of the solutions, and transported at ambient temperatures.

The performance analysis is based on the law of mass and energy conservation. Figure 1 shows also the main status points.

The mass and energy conservation are described as, For the generator,

$$
\begin{aligned}
\dot{m}_{4}+\dot{m}_{10} & =\dot{m}_{5}+\dot{m}_{11} \\
\dot{m}_{4} X_{4}+\dot{m}_{10} X_{10} & =\dot{m}_{5} X_{5}+\dot{m}_{11} X_{11}
\end{aligned}
$$




$$
Q_{G}=\dot{m}_{5} h_{5}+\dot{m}_{11} h_{11}-\dot{m}_{4} h_{4}-\dot{m}_{10} h_{10}
$$

For the rectifier,

$$
\begin{gathered}
\dot{m}_{11}=\dot{m}_{10}+\dot{m}_{12} \\
\dot{m}_{11} X_{11}=\dot{m}_{10} X_{10}+\dot{m}_{12} X_{12} \\
Q_{R}=\dot{m}_{11} h_{11}-\dot{m}_{10} h_{10}-\dot{m}_{12} h_{12}
\end{gathered}
$$

For the condenser,

$$
\begin{gathered}
\dot{m}_{12}=\dot{m}_{13} \\
Q_{C}=\dot{m}_{12} h_{12}-\dot{m}_{13} h_{13}
\end{gathered}
$$

For the evaporator,

$$
\begin{gathered}
\dot{m}_{16}=\dot{m}_{17} \\
Q_{E}=\dot{m}_{17} h_{17}-\dot{m}_{16} h_{16}
\end{gathered}
$$

For the absorber,

$$
\begin{gathered}
\dot{m}_{18}+\dot{m}_{9}=\dot{m}_{1} \\
\dot{m}_{18} X_{18}+\dot{m}_{9} X_{9}=\dot{m}_{1} X_{1} \\
Q_{A}=\dot{m}_{18} h_{18}+\dot{m}_{9} h_{9}-\dot{m}_{1} h_{1}
\end{gathered}
$$

For the throttle valves,

$$
h_{8}=h_{9}, h_{15}=h_{16}
$$

In which, $Q$ means heat energy, $\dot{m}$ means mass flow rate, $h$ means enthalpy, and $X$ means concentration.

For the solution heat exchangers, the efficiency is assumed to be 0.9 .

For the pumping power (only consider the straight pipe pressure loss, not local pressure loss), it is evaluated by,

$$
W_{P}=\sum \frac{V \Delta p}{\eta}=\frac{\dot{m}_{r} \frac{\Delta p_{r}}{\rho_{r}}+\dot{m}_{w} \frac{\Delta p_{w}}{\rho_{w}}+\dot{m}_{a} \frac{\Delta p_{a}}{\rho_{a}}}{\eta}
$$

In which, for rich solution pump,

$$
\Delta p_{r}=\lambda_{r} \rho_{r} \frac{L}{D_{r}} \frac{u_{r}{ }^{2}}{2}+\left(p_{G}-p_{A}\right)
$$

For weak solution pump,

$$
\Delta p_{w}=\lambda_{w} \rho_{w} \frac{L}{D_{w}} \frac{u_{w}{ }^{2}}{2}
$$

For liquid ammonia pump,

$$
\Delta p_{a}=\lambda_{a} \rho_{a} \frac{L}{D_{a}} \frac{u_{a}^{2}}{2}
$$

And,

$$
\begin{gathered}
\lambda=\frac{64}{\operatorname{Re}} \quad(\operatorname{Re}<=2000) \\
\frac{1}{\sqrt{\lambda}}=1.74-2 \log _{10}\left(\frac{2 \varepsilon}{D}+\frac{18.7}{\operatorname{Re} \sqrt{\lambda}}\right)(\operatorname{Re}>2000)
\end{gathered}
$$

The thermal COP and electrical COP are used to evaluate the performance of the cycle.

The thermal coefficient of performance for heating (heating TCOP) and cooling (cooling TCOP) are,

$$
\begin{aligned}
& \operatorname{TCOP}_{c}=\frac{Q_{E}}{Q_{G}} \\
& \operatorname{TCOP}_{h}=\frac{Q_{A}}{Q_{G}}
\end{aligned}
$$

The electric coefficient of performance for heating (heating ECOP) and cooling (cooling ECOP) are,

$$
\begin{aligned}
& \operatorname{ECOP}_{c}=\frac{Q_{E}}{W_{P}} \\
& \operatorname{ECOP}_{h}=\frac{Q_{A}}{W_{P}}
\end{aligned}
$$

The system coefficient of performance for heating (heating COP) and cooling (cooling COP) are,

$$
\begin{gathered}
C O P_{c}=\frac{Q_{E}}{Q_{G}+W_{P}}=\frac{1}{\frac{1}{T C O P_{c}}+\frac{1}{E C O P_{c}}} \\
C O P_{h}=\frac{Q_{A}}{Q_{G}+W_{P}}=\frac{1}{\frac{1}{T C O P_{h}}+\frac{1}{E C O P_{h}}}
\end{gathered}
$$

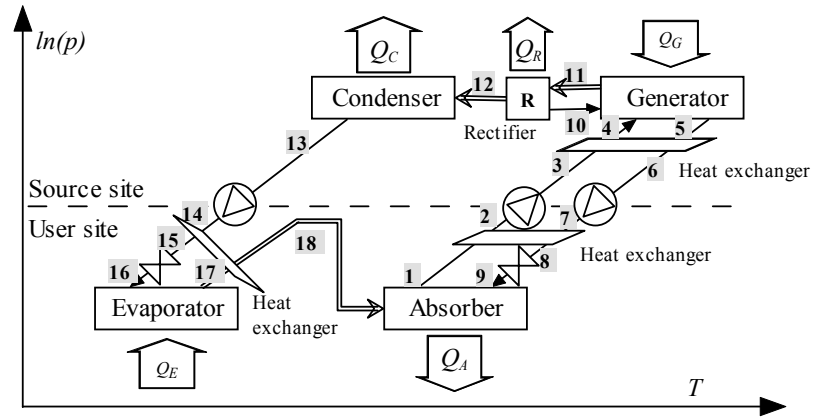

Figure 1. Principle of the ammonia-water absorption heat energy transportation system

\section{ANALYSIS RESULTS AND DISCUSSION}

The basic conditions are listed in Table 1.

Figure 2(a) shows the performance of the model to transport heat at different ambient temperatures. At ambient temperature from $0^{\circ} \mathrm{C}$ to $10^{\circ} \mathrm{C}$, and the absorber temperature of $60^{\circ} \mathrm{C}$, the thermal COP reaches 0.6 , and the electric COP reaches more than 100 . The heat produced is suitable for domestic hot water supply and floor heating.

Figure 2(b) shows the performance of the model to transport cold at different ambient temperatures. At ambient temperature from $25^{\circ} \mathrm{C}$ to $35^{\circ} \mathrm{C}$, and the evaporator temperature of $5^{0} \mathrm{C}$, the thermal COP reaches 0.5 , and the electric COP 
reaches more than 50. The cold produced is suitable for domestic air-conditioning and food preservation.

As shown in figure 2, the electric COPs are more than 100 times of the thermal COPs, so the system COPs are mainly determined by the thermal COPs. The effect of the electric COPs on the system COPs is about $1 \%$, as shown as follows.

$$
\frac{T C O P-C O P}{C O P}=\frac{T C O P-\frac{1}{\frac{1}{E C O P}+\frac{1}{T C O P}}}{\frac{1}{\frac{1}{E C O P}+\frac{1}{T C O P}}}=\frac{T C O P}{E C O P} \approx 0.01
$$

The ammonia-water absorption heat transportation system consumes only small quantity of power to transport a great amount of waste heat over long distance, and it can produce heat or cold according to different seasons. The simulation shows that it has great potential to make good use of the waste heat from the industry zones or power stations to save primary energy.

Tab.1 Basic conditions for the performance analysis

\begin{tabular}{|c|c|c|c|}
\hline Parameters & $\begin{array}{c}\text { Symbo } \\
\mathbf{l}\end{array}$ & Basic value & Unit \\
\hline Ambient temperature & $T_{a m b}$ & $0,10,25,35$ & ${ }^{0} \mathrm{C}$ \\
\hline Generator temperature & $T_{G}$ & 105 & ${ }^{0} \mathrm{C}$ \\
\hline Condenser temperature & $T_{C}$ & $\mathrm{~T}_{\mathrm{amb}}+5$ & ${ }^{0} \mathrm{C}$ \\
\hline $\begin{array}{c}\text { Evaporator } \\
\text { temperature }\end{array}$ & $T_{E}$ & $\mathrm{~T}_{\mathrm{amb}}-5$ & ${ }^{0} \mathrm{C}$ \\
\hline Absorber temperature & $T_{A}$ & $\mathrm{~T}_{\mathrm{amb}}+5$ & ${ }^{0} \mathrm{C}$ \\
\hline Waste Heat source & $Q_{G}$ & 500 & $\mathrm{MW}$ \\
\hline Transportation distance & $L$ & 50 & $\mathrm{~km}$ \\
\hline $\begin{array}{c}\text { Pipe diameter } \\
\text { of rich solution }\end{array}$ & $D_{r}$ & 1.2 & $\mathrm{~m}$ \\
\hline $\begin{array}{c}\text { Pipe diameter } \\
\text { of rich solution }\end{array}$ & $D_{w}$ & 1.0 & $\mathrm{~m}$ \\
\hline $\begin{array}{c}\text { Pipe diameter } \\
\text { of ammonia liquid }\end{array}$ & $D_{a}$ & 0.6 & $\mathrm{~m}$ \\
\hline Roughness of pipes & $\varepsilon$ & 0.3 & $\mathrm{~mm}$ \\
\hline
\end{tabular}

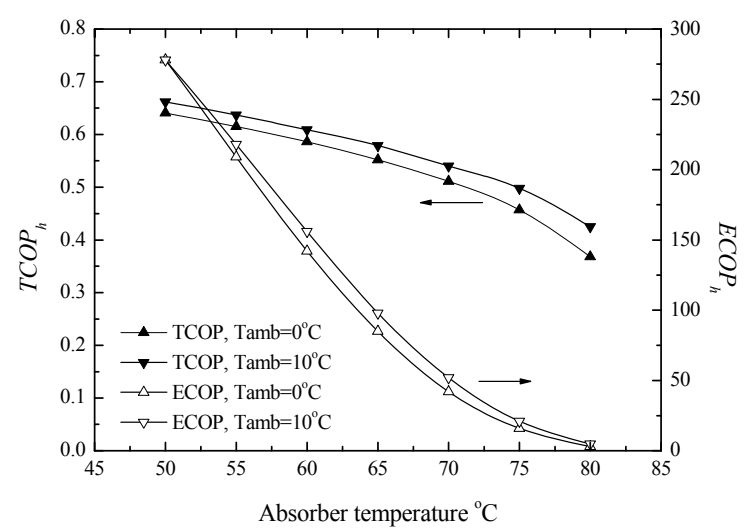

(a) TCOP and ECOP of heat transportation

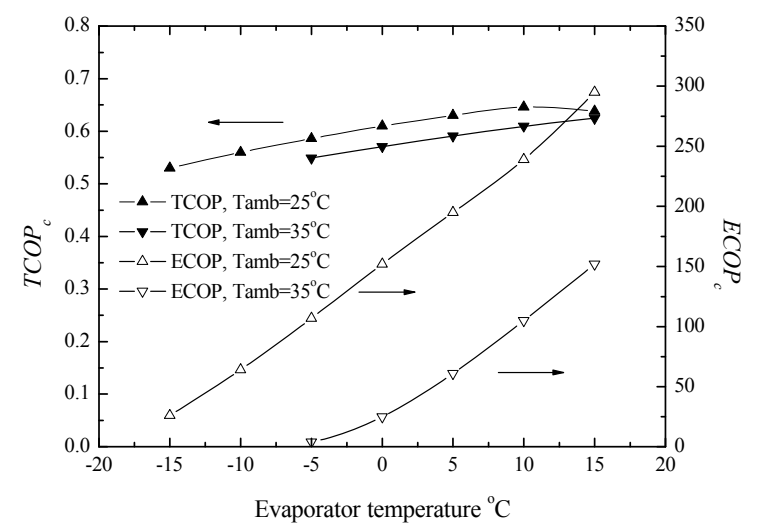

(b) TCOP and ECOP of cold transportation

Figure 2. TCOP and ECOP of heat and cold transportation at different ambient temperatures

The three liquids transported over long distance are exposed at ambient temperatures, this leads to a mount of heat loss. Suppose heat with absorbing temperature of $60^{\circ} \mathrm{C}$ is produced at the user site when the ambient temperature is lower than $20^{\circ} \mathrm{C}$ and cooing with evaporating temperature of $0^{\circ} \mathrm{C}$ is produced when the ambient temperature is higher than $25^{\circ} \mathrm{C}$, Figure 8 shows the relative loss (ratio of the heat loss through transportation to the heat inputted into the generator) of the three liquids transported. The circulating ratio (ratio of flow rate of rich solution to ammonia liquid) is also shown in Figure 3.

The heat loss of the rich solution through transportation is obviously more than that of the ammonia liquid and the weak solution due to the inadequate heat exchange by the solution heat exchanger at the user site. When heating is produced at low ambient temperatures, the flow rate and the specific heat of the rich solution are greater than those of the weak solution, so the temperature of the rich solution flowing out of the heat exchanger is fairly higher than that of the ambient. This leads to a big amount of heat loss. When cooling is produced at high ambient temperatures, the heat exchanger at the user site does not work, and the heat loss is mainly affected by the flow rate, i.e. the circulating ratio.

Figure 4 shows the pressure drop and the relative power consumption (ratio of the power consumption through transportation to the heat input into the generator) of the liquids transported, in which the pressure difference between the generator and the absorber is included. When the diameters are fixed, the pressure drop and the power consumption are mainly affected by the flow rates, i.e. the circulating ratio. The pressure of each liquid is normally not more than $1.5 \mathrm{MPa}$, and the power consumption is not more than $1 \%$ of the heat input into the generator. This result is accordant with formula (27).

The ammonia-water absorption heat transportation system consumes only small quantity of power to transport a great amount of waste heat over long distance, and it can produce heating or cooling according to the demands in different seasons. The simulation shows that it has great potential to 
make good use of the waste heat from the industry zones or power stations to save primary energy.

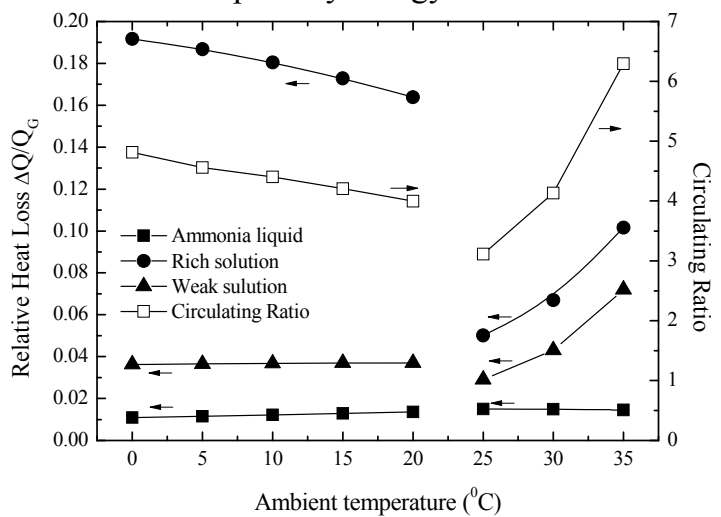

Figure 3 Relative heat loss through transportation at different ambient temperatures

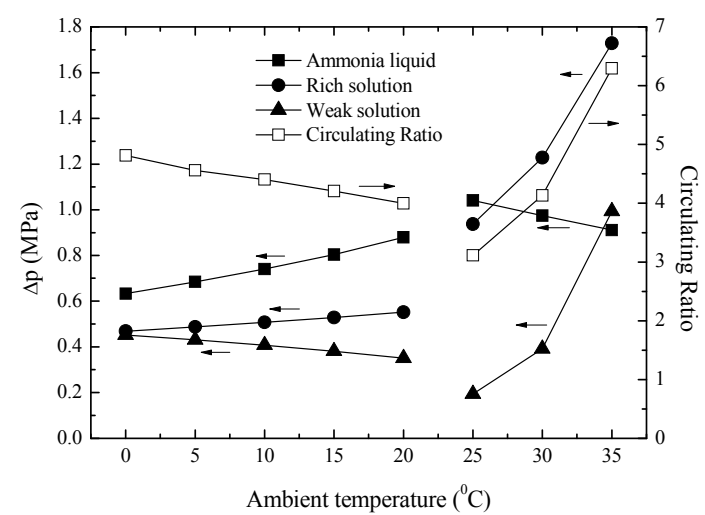

(a)

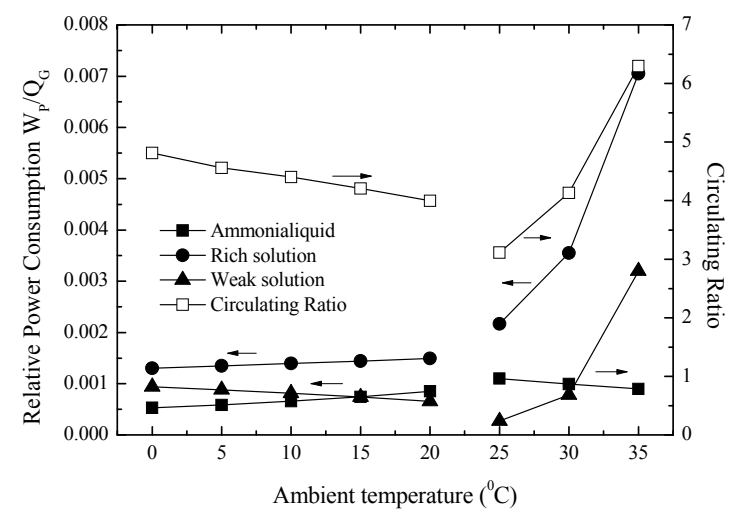

(b)

Figure 4 Pressure drop and relative power consumption through transportation at different ambient temperatures. (a) Pressure drop. (b) Power consumption.

\section{EXPERIMENTAL DESIGN AND RESULTS}

\subsection{Prototype design and setup}

A small-size prototype is built to investigate the performance of the ammonia-water absorption heat energy long-distance transportation system. Figure 5 shows the outline of the experimental prototype. The main design parameters are listed in Table 2.

The prototype is composed of nine main components, i.e. the generator, the rectifier, the partial condenser, the main condenser, the evaporator, the absorber, the solution pump, the solution heat exchanger at the source site and the other at the user site, and the long-distance transportation coils (30 $\mathrm{m}$ as a demonstration).

The generator is driven by an electric heater. The heat is transmitted to the inner side of the generator by radiation, and then the solution is heated to be boiled. The rectifier is a packed column, in which the wire-mesh packing is used. The equivalent plate number of the packing is $10-12 / \mathrm{m}$. In the rectifier the height of the packing is $0.9 \mathrm{~m}$. The partial condenser, the main condenser, the evaporator and the absorber are designed as falling-film heat exchangers. The solution heat exchangers are designed as modified countercurrent coil exchangers. The solution heat exchanger at the user site is integrated at the bottom of the rich solution tank. The solution pump is a flow control membrane pump, and its flow rate can be adjusted from $10 \%$ to $100 \%$ within the operating range. The three pipelines of $30 \mathrm{~m}$ for the long-distance transportation are designed as three coils. Their inner diameters are $5 \mathrm{~mm}$, and the velocity of the liquids varies from 1 to $3 \mathrm{~m} / \mathrm{s}$ according to different operating conditions.

Tab.2 Main design parameters of the experimental prototype

\begin{tabular}{|l|l|l|l|}
\hline Parameters & $\begin{array}{l}\text { Symbo } \\
\text { l }\end{array}$ & $\begin{array}{l}\text { Basic } \\
\text { value }\end{array}$ & $\begin{array}{l}\text { Uni } \\
\text { t }\end{array}$ \\
\hline Heat source & $Q_{G}$ & 2.0 & $\mathrm{~kW}$ \\
\hline Transportation distance & $L$ & 30 & $\mathrm{~m}$ \\
\hline Pipe diameter of rich solution & $D_{r}$ & 0.05 & $\mathrm{~m}$ \\
\hline Pipe diameter of rich solution & $D_{w}$ & 0.05 & $\mathrm{~m}$ \\
\hline $\begin{array}{l}\text { Pipe diameter of ammonia } \\
\text { liquid }\end{array}$ & $D_{a}$ & 0.05 & $\mathrm{~m}$ \\
\hline
\end{tabular}

\subsection{Experimental results}

The experimental work includes two parts, one is to produce heating, and the other is to produce cooling. In the condition of heating, the hot water is put into the absorber, and the cooling water is put into the partial condenser, the main condenser and the evaporator, while in the condition of cooling, the chilled water is put into the evaporator, and the cooling water is put into the partial condenser, the main condenser and the absorber. The generating temperature is kept at about $95^{\circ} \mathrm{C}$.

The thermal coefficient of performance is calculated as follows according to the experimental data.

$$
\operatorname{TCOP}_{h}=\frac{Q_{A}}{Q_{G}}=\frac{\dot{m}_{A, w} \times c_{w} \times\left(T_{A, \text { out }}-T_{A, \text { in }}\right)}{Q_{G}}
$$




$$
\operatorname{TCOP}_{c}=\frac{Q_{E}}{Q_{G}}=\frac{\dot{m}_{E, w} \times c_{w} \times\left(T_{E, \text { in }}-T_{E, \text { out }}\right)}{Q_{G}}
$$

In which, $\dot{m}_{A, w}$ and $\dot{m}_{E, w}$ mean the mass flow rate of the cooling water into the absorber and the chilled water into the evaporator, respectively. $c_{w}$ means the specific heat capacity of the water. $T_{A, \text { in }}$ and $T_{A \text {,out }}$ mean the temperatures of the input and output cooling water of the absorber. $T_{E, \text { in }}$ and $T_{E, \text { out }}$ mean the temperatures of the input and output chilled water of the evaporator.

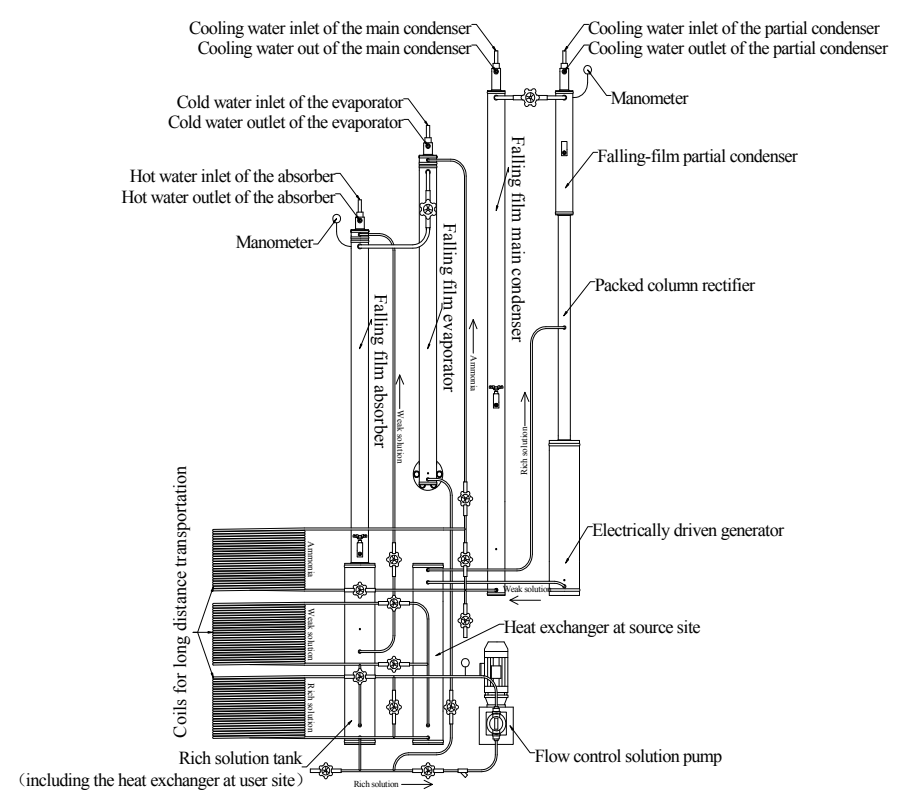

Figure 5. Outline of the experimental prototype

Figure 6 shows the thermal COP for heating and cooling at different cooling water temperatures. It can been seen from figure 6(a) that the thermal COP for heating is over 0.5 when the output hot water temperature is not higher than $55^{\circ} \mathrm{C}$, and the corresponding input hot water temperature is about $50^{\circ} \mathrm{C}$, which is proper for domestic hot water supply and floor heating. The experimental data are about $10 \%$ lower than the theoretical analysis by the aforementioned model. This result can be predicted because the prototype is designed in small size (the heating output is only about $1 \mathrm{~kW}$ ), and the performance is very sensitive to the heat loss of the system. Figure $6(\mathrm{~b})$ shows that the thermal COP for cooling is over 0.4 when the output chilled water temperature is not lower than $5^{\circ} \mathrm{C}$, and the corresponding input cold water temperature is about $10^{\circ} \mathrm{C}$, which is proper for domestic air-conditioning and food preservation. When the input chilled water temperature gets low, the thermal COP gets down sharply. On one hand, it is due to the heat loss of the system, on the other hand, the concentration of the solutions filled in the system (about 30$38 \%$ for the weak solution and $40-48 \%$ for the rich solution, which are adjusted by the ammonia tank) are not suitable for relative low evaporator temperatures.

The electric COP is not considered because the efficiency of the solution pump for this small-size prototype is too low, and it is very difficult to simulate the actual long-distance transportation application.

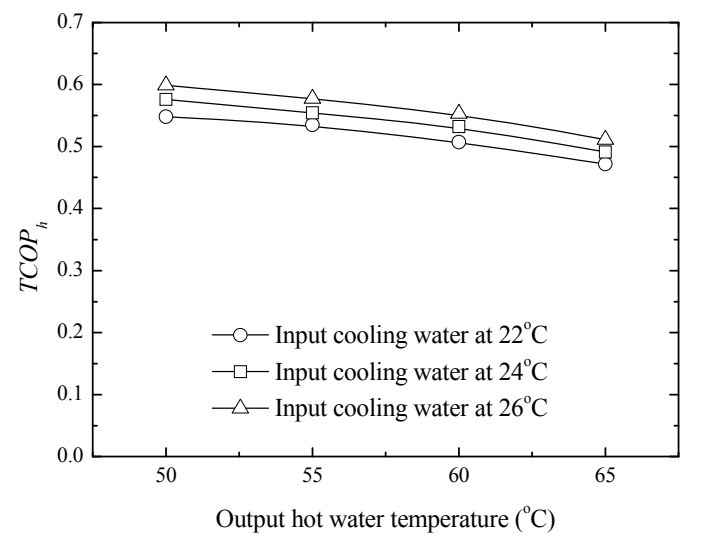

(a) Experimental TCOP of heat transportation

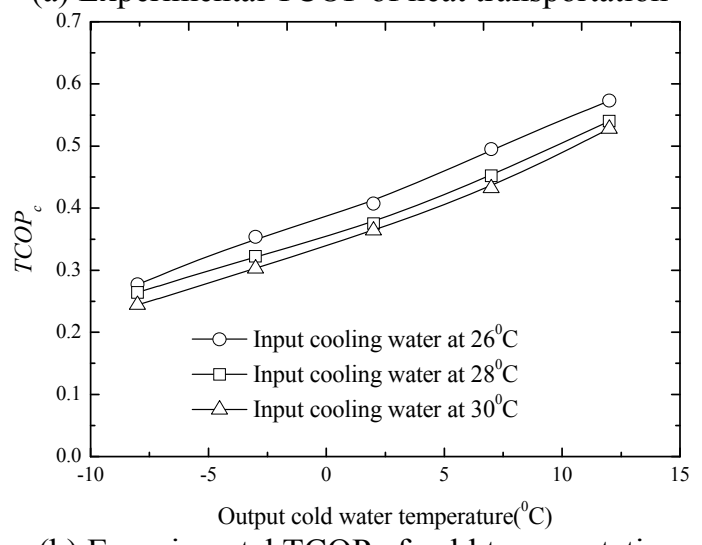

(b) Experimental TCOP of cold transportation

Figure 6. Experimental performance of the small-size prototype

\section{CONCLUSION}

This study develops a model of ammonia-water absorption heat energy transportation over long distance and the performance analysis shows satisfactory results. The transportation of heat or cold can either reaches high performance in the practical temperature range. In the temperature range for domestic use, for example, around $55{ }^{\circ} \mathrm{C}$ for hot water supply and floor heating and around $8^{0} \mathrm{C}$ for airconditioning and food preservation, the thermal coefficient of performance can both reach to 0.5 , and the electrical coefficient of performance can both reach higher than 50. A small-size prototype for the heat energy transportation over long distance is built to verify the performance analysis. In the practical temperature range for domestic use (around $55^{\circ} \mathrm{C}$ for heating and around $8^{\circ} \mathrm{C}$ for cooling), the experimental and the analytical results show good accordance. 
This work shows that the ammonia-water absorption system is suitable to transport heat or cold over long distance. In this way, the power consumption of big cities for aircondition in summer, heating in winter and hot water supply all through the year can be greatly reduced if the waste heat can be transported from the waste heat sites, for example, nuclear power stations and big industry zones, which are located several tens of kilometers away from the user sites.

\section{ACKNOWLEDGMENTS}

This work is supported by Shanghai Municipal Science and Technology Committee (Grant No.06SR07106) in China, and Shanghai Pujiang Program (Grant No.06PJ14061) in China. This work is also supported by the Programme Interdisciplinaire Energie du CNRS - "VALOTHERM" in France.

\section{REFERENCES}

[1] Liu Q S, Yabe A, Kajiyama S and Jukuda K. A review of study on thermal energy transport system by synthesis and decomposition reactions of methanol. JSME International Journal 2002, Serious B, 45(3).

[2] Fujita Y, Shikata I, Kawai A and Kamano H. Latent heat storage and transportation system "TransHeat Container". IEA/ECES Annex 18, the First workshop and Expert Meeting, $13^{\text {th }}-15^{\text {th }}$ November, 2006, Tokyo, Japan.

[3] Ogura H. Waste heat recycling system using chemical heat pump container. IEA, ECES IA Annex 17, Advanced thermal energy storage through phose change materials and chemical reactions-feasibility studies and demonstration projects. $3^{\text {rd }}$ Workshop, 1-2 October 2002, Tokyo, Japan.

[4] Kato Y. Possibility of chemical heat storage in thermal energy transportation market. IEA, ECES IA Annex 18, Transportation of Energy utilizing Thermal Energy Storage Technology. $1^{\text {st }}$ Workshop, 13-15 November 2006, Tokyo, Japan.

[5] Kang BH and Yabe A, Performance analysis of a metal- hydride heat transformer for waste heat recovery. Applied Thermal Engineering 1996; 16(8-9):677-690.

[6] Takeda H, Kabutomori T, Y. Wakisaka and K. Ohnishi. Characteristics of heat-hydrogen gas energy conversion and hydrogen gas transportation using hydrogen absorbing alloy. Journal of Alloys and Compounds 1997; 253-254:677-681.

[7] Nasako K, Ito Y and Osumi M. Intermittent heat transport using hydrogen absorbing alloys. International Journal of Hydrogen Energy 1998; 23(9):815-824.

[8] Nasako K, Ito $Y$ and Osumi M. Long-distance heat transport system using a hydrogen compressor. International Journal of Hydrogen Energy 1998; 23(10):911-919.

[9] Berthiaud J, Mazet N, Luo L, Stitou D and Descamps I. Long-distance transport of thermal energy using sorption cycles. Proc. ATI Conference, Milano, Italy, 14-17 May 2006.

[10] Stitou D, Spinner B and Mazet N. New sorption cycles for heat and/or cold production adapted for long distance heat transmission. ASME, Advanced Energy Systems Division AES 2002; 42:441-446.

[11] Kang Y T, Akisawa A, Sambe Y and Kashiwagi T. Absorption heat pump systems for solution transportation at ambient temperature-STA cycle. Energy 2000; 25:355370.

[12] Akisawa A, Hamamoto Y and Kashiwagi T. Performance of thermal energy transportation based on absorption system -Solution transportation absorption chiller-. International Sorption Heat Pump Conference, June 2224, 2005; Denver, CO, USA.

[13] Jo Y K, Kim J K, Lee S G and Kang Y T. Development of type 2 solution transportation absorption system for utilizing LNG cold energy. International Journal of Refrigeration 2007; 30:978-985. 